\title{
Long-term extrapolation of properties of polymeric waterproofing membranes
}

\author{
M. Farshad ${ }^{1}$, S. Bianchi ${ }^{2}$ and Ch. Löwe ${ }^{1}$ \\ (1) Empa, Swiss Federal Laboratories of Materials for Testing and Research, Department Materials and Systems for Civil \\ Engineering, Überlandstrasse 129, CH-8600 Dübendorf, Switzerland \\ (2) Swiss Federal Institute of Technology (ETHZ), Zurich, Switzerland
}

Received: 29 November 2004; accepted: 28 January 2005

\begin{abstract}
The expected increasing duration of service life of polymeric materials requires suitable test and extrapolation methods for an assessment of the aging effects under various loads and exposures. Taking data from polymeric waterproofing membranes after aging in water at elevated temperatures as an example, the applicability of the time-temperature superposition (TTS) principle for extrapolation is investigated. Some problems and limitations are highlighted.

1359-5997 (O 2005 RILEM. All rights reserved.

\section{RÉSUMÉ}

L'accroissement attendu de la durée de vie des matériaux polymères nécessite des méthodes d'extrapolation adéquates pour prendre en compte les effets du vieillissement sous diverses sollicitations et expositions. En prenant comme exemple des données expérimentales obtenues pour le vieillissement en eau chaude de membranes d'étanchéité polymériques, l'applicabilité du principe TTS pour l'extrapolation est investiguée. Quelques limitations et problèmes sont discutés.
\end{abstract}

\section{INTRODUCTION}

Polymeric materials are increasingly used in applications with expected service life durations of several years or even several decades. Specific properties of recently developed polymers have become comparable to those of conventional materials (e.g., metals, ceramics), and, on the other hand, offer some advantages (e.g. light-weight). Time, temperature and exposure to media are the main factors in aging of polymeric materials, through both, physical and chemical processes. The service life duration of polymers has become an area of active research, and long-term properties are intensively studied (see e.g., $[1,2]$ ).

One approach towards the prediction of long-term behavior is the use of suitable extrapolation models applied to short-term test results. Typical service life durations may reach 50 years or more, especially in civil engineering. applications, e.g. plastic pipes or water-proofing membranes.

This approach is explained and discussed in the present contribution by determining activation energies through application of the Ozawa model $[3,4]$ to data from thermogravimetric analysis (TGA) on polymeric waterproofing membranes. The extrapolation is then based on the time-temperature superposition principle [5].

\section{EXTRAPOLATION MODELS}

If changes occur as thermally activated processes at different time scales, the processes are always temperaturedependent. A temperature increase, for example, accelerates movements on the molecular level and thus yields thermal equilibrium faster, and all visco-elastic processes.

Beside the Ozawa model with two shift-factors (horizontal and vertical), other popular models for determination of the activation energy of any thermally-activated aging process are: (1) the Arrhenius model, and (2) the Eyring-model.

The Arrhenius-model is described by Equation (1), with $\mathrm{t}=$ time, $\mathrm{A}=$ frequency factor, $\mathrm{G}=$ activation energy (in $\mathrm{J} / \mathrm{mol}$ ), $\mathrm{T}=$ temperature (in $\mathrm{K}$ ), and $\mathrm{R}$ the universal gas constant (equal to $8.314 \mathrm{~J} / \mathrm{K} \mathrm{mol}$ ) 
$t=A e^{G / R T}$

This Arrhenius equation (see e.g., [5] for details) typically describes linear visco-elastic processes or the activation energy of chemical reactions. It is, however only valid as long as the reaction mode is not changing. If other parameters, e.g., diffusion speed, determine the reaction, it can not be applied.

The generalized Eyring-model (see e.g., [5] for details) is described by Equation (2). It constitutes an extension of the Arrhenius model (Equation (1)) incorporating a temperature-dependent frequency factor $\mathrm{A}$.

$\frac{t_{2}}{t_{1}}=\frac{T_{2}}{T_{1}} e^{\left[G / R\left(\frac{1}{T_{2}}-\frac{1}{T_{1}}\right)\right.} e^{E\left(C+\frac{D}{R T_{1}}\right)-F\left(C+\frac{D}{R T_{2}}\right)}$

C, D, E and F are constants.

The so-called time-temperature-superposition principle is of a more general nature and can be applied even if the aging process is changing with time. It is based on experimental measurements of a material property with time, taken at different temperatures. When plotted on double-logarithmic scales, the group of curves obtained at different temperatures can be shifted (by applying suitably chosen horizontal and vertical shift factors) until a so-called "master"-curve for a desired temperature is established. Changes in material properties, e.g., the ductile to brittle transition in thermoplasts with two different slopes for stress-time curves (plotted on double-logarithmic scales), then form a "knee"-point on this master curve. This behavior can be described by Equation (3), with $\sigma=$ stress, $\mathbf{t}=$ time, $\alpha$ and $\mathrm{A}$ coefficients (to be determined for each range separately), with $\alpha$ sometimes depending on time.

$\log \sigma=\frac{A}{\alpha}-\frac{\log t}{\alpha}$

There are various approaches for determining the horizontal and vertical shift factors. A simplified horizontal shift factor for polyethylene (PE) is, e.g., described in [5], another description is the so-called Williams-Landel-Ferry equation (see, e.g., [6]). The latter is used to describe the behavior of polymers near the glass transition point, assuming that viscosity is rapidly decreasing with increasing free volume.

\section{DATABASE}

Waterproofing membranes made from thermoplastic polymers (PVC-P or poly-olefins) are widely used in roofing and tunneling applications, as well as in waste-deposits. Different types of waterproofing membranes have been aged under various conditions [7]. The thermogravimetric analyses on specimens of these membranes stored in water at temperatures of $+23^{\circ} \mathrm{C},+45^{\circ} \mathrm{C}$, and $+70^{\circ} \mathrm{C}$ for one year were performed on a thermal balance TGA 7 of Perkin Elmer. Mass changes were measured as a function of temperature within a temperature range from ambient temperatures to $900^{\circ} \mathrm{C}$ applying heating rates of 20 and $50 \mathrm{~K} / \mathrm{min}$ respectively. The initial inert helium atmosphere was changed to oxygen at $600^{\circ} \mathrm{C}$ at a constant flow rate of $25 \mathrm{~mL} / \mathrm{min}$. According to the Ozawa model, the activation energy was calculated and extrapolated via the TTS principle. The experimentally determined mass changes after 3,6 and 12 months aging also contributed to the extrapolation, which are discussed in the following.

\section{APPLICATION OF EXTRAPOLATION MODELS}

\subsection{Activation energy}

The Ozawa model $[3,4]$ yields the activation energy from experimentally determined TGA data. The mass change is described by Equation (4) with $W=$ remaining weight, $A=$ frequency factor, $G=$ activation energy, $R=$ universal gas constant, $T=$ temperature, $t=$ time, $n=$ order of reaction kinetics

$-\frac{d W}{d t}=A e^{-\frac{G}{R T}} W^{n}$

This model was applied for determining the activation energy of low-density polyethylene (PE-LD, Table 1) and plasticized polyvinylchloride (PVC-P) using the TGA data (heating rates $20 \mathrm{~K} / \mathrm{min}$ and $50 \mathrm{~K} / \mathrm{min}$ ) on specimens taken from waterproofing membranes.

After determining the order of the reaction kinetics (equal to 1 in the case of PE-LD), the remaining mass as a function of temperature can be described by equation (4) and the data are shown in Fig. 1.

The analogous experiment for specimens from a waterproofing membrane made of PVC-P yielded a more complicated, tri-partite curve. Equation (4) has, therefore, been partitioned into three temperature ranges with three different activation energies, and the results are shown in Fig. 2. For each subsequent range, the contribution from the preceding range has been subtracted for determining the theoretical curve shown in Fig. 2.

Although an extrapolation for an olefinic based

\begin{tabular}{|}
$\begin{array}{l}\text { Table 1 - Activation energy determined from } \\
\text { thermo-gravimetric analysis (TGA) via the Ozawa } \\
\text { model (see text for details) }\end{array}$ \\
\hline $1 / \mathrm{T}\left[1 /{ }^{\circ} \mathrm{K}\right]$ & $\mathrm{W}^{*}[\%]$ & $\mathrm{G}[\mathrm{J} / \mathrm{mol}]$ & $\log (\mathrm{A})$ \\
\hline 0.00134 & 71.7805 & 241483 & 16.39 \\
\hline 0.00131 & 51.2291 & 241483 & 16.41 \\
\hline 0.00130 & 32.3416 & 241483 & 16.43 \\
\hline 0.00129 & 20.9213 & 241483 & 16.41 \\
\hline 0.00127 & 8.3828 & 241483 & 16.39 \\
\hline & & mean value & mean value \\
& & 241483 & 16.41 \\
\hline & $\mathrm{R}\left[\mathrm{J} /{ }^{\circ} \mathrm{Kmol}\right]$ & & $\mathrm{A} \mathrm{[1/min}]$ \\
& 8.3140 & & $2.55 \mathrm{E}+16$ \\
\hline
\end{tabular}

* $\mathrm{W}=$ measured remaining specimen weight in $\%=$ weigh measured / initial weight * $100 \%$

** $A=$ frequency factor 
PE-LD

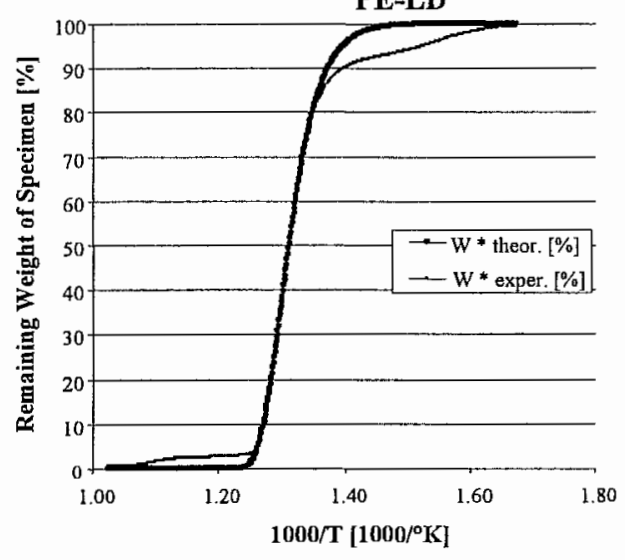

Fig. 1 - A comparison between the theoretical (thick) and experimental curve (thin) of the remaining weight of a PE-LD specimen in a TGA analysis with a heating rate of $20 \mathrm{~K} / \mathrm{min}$, $\mathrm{PE}-\mathrm{LD}$ specimen taken from a waterproofing membrane.

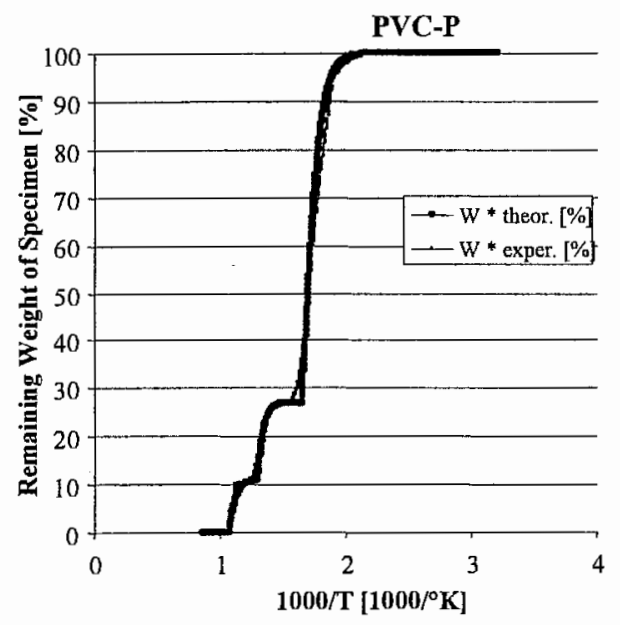

Fig. 2 - A comparison between the theoretical and experimental curve of the remaining weight of a PVC-P specimen in a TGA analysis with a heating rate of $20 \mathrm{~K} / \mathrm{min}$, PVC-P specimen taken from a waterproofing membrane. The equation describing the Ozawa model has been partitioned into three separate ranges.

waterproofing membrane was established, only the results of the long term extrapolation for a PVC sample are given in this paper.

\subsection{Time-temperature-superposition (TTS) principle}

The Time-TemperatureSuperposition principle is applied here to correlate the experimentally determined mass change after one year storage in media (water, in this case) at three different temperatures. The principle is then used to extrapolate the mass change of a PVC-

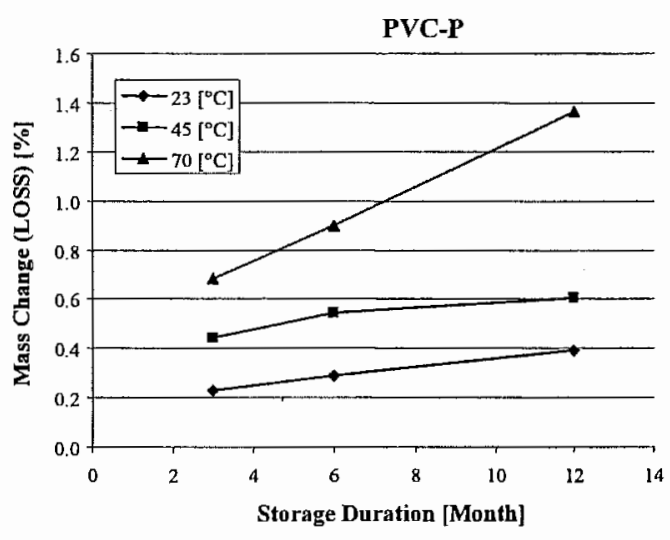

Fig. 3 - Experimental data for the mass change of PVC-P waterproofing membranes aged in water at temperatures of $+23^{\circ} \mathrm{C},+45^{\circ} \mathrm{C}$, and $+70+\mathrm{C}$ for one year (measurements after 3,6 and 12 months). The mass is decreasing with storage duration.

$\mathrm{P}$ membrane material to 100 year service life at two temperatures $\left(+23^{\circ} \mathrm{C}\right.$ and $\left.+45^{\circ} \mathrm{C}\right)$. The experimental data base, i.e. the mass change versus time at three different temperatures is shown in Fig. 3.

The curves for $+23^{\circ} \mathrm{C}$ and $+70^{\circ} \mathrm{C}$ have been shifted using the horizontal and vertical shift factors shown in Equations (5) and (6), respectively [5].

$$
\begin{aligned}
& \Delta h=\frac{1}{\ln 10} \frac{G}{R}\left(\frac{T_{1}-T_{2}}{T_{1} T_{2}}\right) \\
& \Delta v=c\left(\frac{T_{1}-T_{2}}{T_{1} T_{2}}\right)
\end{aligned}
$$

These shift factors and the data used to establish the master curve are compiled in Table 2.

The resulting superposition and extrapolation is shown in Fig. 4. The same base data have also been used to establish a master curve for $+23^{\circ} \mathrm{C}(296 \mathrm{~K})$. The values are summarized in Table 3. The superposition and extrapolation is shown in Fig. 5.

An approximation for the shift factors for different temperatures can be estimated by linear interpolation of the shift factors obtained for the given temperatures.

\section{DISCUSSION}

The Arrhenius approach would require data from time-

\begin{tabular}{|c|c|c|c|c|c|c|c|}
\hline & \multirow{2}{*}{\multicolumn{3}{|c|}{$\log$ (mass change) }} & \multicolumn{2}{|c|}{ Shift factors for $\mathrm{T}=296 \mathrm{~K}$} & \multicolumn{2}{|c|}{ Shift factors for $\mathrm{T}=343 \mathrm{~K}$} \\
\hline & & & & $\Delta \mathrm{h}$ & $\Delta \mathrm{v}$ & $\Delta \mathrm{h}$ & $\Delta \mathrm{v}$ \\
\hline & \multicolumn{3}{|c|}{ Temperature } & {$[\log (\mathrm{M})]$} & {$[\log (\%)]$} & {$[\log (\mathrm{M})]$} & {$[\log (\%)]$} \\
\hline Log(Time) & \multirow{2}{*}{$\begin{array}{l}296 \\
{[\mathrm{~K}]}\end{array}$} & \multirow{2}{*}{$\begin{array}{l}318 \\
{[\mathrm{~K}]}\end{array}$} & \multirow{2}{*}{$\begin{array}{l}343 \\
{[\mathrm{~K}]}\end{array}$} & 1.34 & 0.10 & 1.32 & 0.10 \\
\hline$[\log (\mathrm{M})]$ & & & & \multicolumn{2}{|c|}{$\log$ (Time) $-\Delta h \log ($ Mass $)-\Delta v$} & \multicolumn{2}{|c|}{$\log ($ Time $)-\Delta h \log ($ Mass $)+\Delta v$} \\
\hline 0.48 & -0.64 & -0.36 & -0.17 & -0.87 & -0.74 & 1.79 & -0.07 \\
\hline 0.78 & -0.54 & -0.27 & 0.05 & -0.56 & -0.64 & 2.1 & 0.05 \\
\hline 1.08 & -0.41 & -0.22 & 0.13 & -0.26 & -0.51 & 2.4 & 0.23 \\
\hline
\end{tabular}
temperature tests rather than from mass change with 


\begin{tabular}{|c|c|c|c|c|c|c|c|}
\hline & \multirow{2}{*}{\multicolumn{3}{|c|}{$\log$ (mass change) }} & \multicolumn{2}{|c|}{ Shift factors for $\mathrm{T}=296 \mathrm{~K}$} & \multicolumn{2}{|c|}{ Shift factors for $\mathrm{T}=343 \mathrm{~K}$} \\
\hline & & & & $\Delta \mathrm{h}$ & $\Delta v$ & $\Delta \mathrm{h}$ & $\Delta \mathrm{v}$ \\
\hline & \multicolumn{3}{|c|}{ Temperature } & {$[\log (\mathrm{M})]$} & {$[\log (\%)]$} & {$[\log (\mathrm{M})]$} & {$[\log (\%)]$} \\
\hline $\log ($ Time $)$ & \multirow{2}{*}{$\begin{array}{l}296 \\
{[\mathrm{~K}]}\end{array}$} & \multirow{2}{*}{$\begin{array}{l}318 \\
{[\mathrm{~K}]}\end{array}$} & \multirow{2}{*}{$\begin{array}{l}343 \\
{[\mathrm{~K}]}\end{array}$} & 1.04 & 0.11 & 1.32 & 0.10 \\
\hline$[\log (M)]$ & & & & \multicolumn{2}{|c|}{$\log ($ Time $)-\Delta \mathrm{h} \log ($ Mass $)-\Delta v$} & \multicolumn{2}{|c|}{$\log ($ Time $)-\Delta h \log ($ Mass $)+\Delta v$} \\
\hline 0.48 & -0.68 & -0.42 & -0.07 & 1.52 & -0.31 & 2.70 & 0.17 \\
\hline 0.78 & -0.57 & -0.29 & 0.02 & 1.82 & -0.18 & 3.00 & 0.26 \\
\hline 1.08 & -0.46 & -0.20 & & 2.12 & -0.09 & & \\
\hline
\end{tabular}

The main assumption for such application is that chemical and molecular changes do not occur in the material.

\section{SUMMARY AND OUTLOOK}

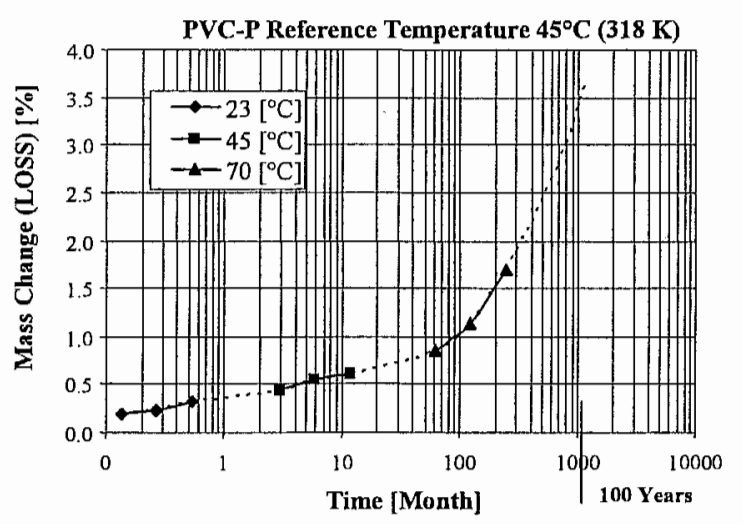

Fig. 4 - Superposition and extrapolation to 100 year service life for material from a PVC-P waterproofing membrane stored in water at $+45^{\circ} \mathrm{C}$, the estimated mass loss after 100 years amounts to about $3.7 \%$

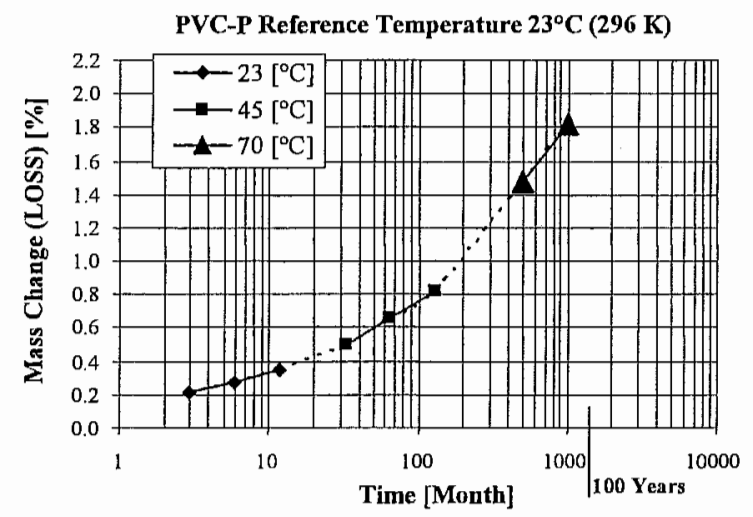

Fig. 5 - Superposition and extrapolation to 100 year service life for material from a PVC-P waterproofing membrane stored in water at $+23^{\circ} \mathrm{C}$, the estimated mass loss after 100 years amounts to about $1.8 \%$.

temperature. The Ozawa-model, on the other hand, which is formally related to the Arrhenius model, yielded the activation energies for both materials, even for PVC-P showing three distinct temperature ranges with different activation energies. Quantitative varieties in the activation energies due to experimental uncertainties may influence the value of the extrapolated data. The features of the curves such as Fig. 2 are, however, not expected to undergo qualitative variations.

The Time-Temperature-Superposition has been shown to be an appropriate procedure for extrapolating experimentally observed mass changes to service life durations of up to 100 years, if two shift factors (horizontal and vertical) are applied.
The Arrhenius-model can be applied for linear behavior of the properties (e.g., logarithmic exposure duration versus inverse temperature). If linear ranges with different slopes are observed, the activation energy has to be determined for each range separately. The Eyring-model is an empirical extension of the Arrheniusmodel that can be applied if non-linear plots are observed.

The Ozawa-model for the analysis of thermogravimetric (TGA) data yielded useful activation energies for the TimeTemperature-Superposition model. PVC-P specimens yielded three different ranges in the TGA data that could still be fitted in a tri-partite model.

The Time-Temperature-Superposition with horizontal and empirically defined vertical shift factors yielded first extrapolations up to 100 years of service life for PVC-P waterproofing membrane material. The extrapolated value indicated mass losses of about $1.8 \%$ at $+23^{\circ} \mathrm{C}$ and of about $3.7 \%$ at $+45^{\circ} \mathrm{C}$.

\section{ACKNOWLEDGEMENTS}

The technical assistance of A. J. Brunner, L. DeBoni, M. Heusser, H. Kramer and D. Völki is gratefully acknowledged.

\section{REFERENCES}

[1] Brown, R.P., 'Predictive techniques and models for durability tests', Polym. Test. 14 (1995) 403-414.

[2] Wallner, G.M., Weigl, C., Leitgeb, R. and Lang, R.W., 'Polymer films for solar energy applications - thermoanalytical and mechanical characterization of aging behavior', Polym. Degrad. Stab. 85 (2004) 1065-1070.

[3] Ozawa, T., 'A new method of analyzing thermogravimetric data', Bull. Chem. Soc. of Japan 38 (11) (1965) 1881-1886.

[4] Still, R.H., 'The use and abuse of thermal methods of stability assessment' in 'Developments in polymer degradation-1', Ed. by Grassie, N., (Applied Science Publishers, London 1979) 1-41.

[5] Cudnovsky, A., Baron, D. and Shulkin, Y., 'Lifetime, toughness and reliability of engineering thermoplastics', in Aging of Material and Methods for the Assessment of Lifetimes of Engineering Plants, CAPA '97, Cape Town, South Africa, April 1997 (A.A. Balkema, Rotterdam, 1997) 297-307.

[6] Billmeyer, F.W., 'Textbook of Polymer Science', $2^{\text {nd }}$ edn (Wiley-Interscience, New York 1971) 199-201.

[7] Flüeler, P., Farshad, M., Löwe, Ch., Kramer, H., Böhni, P. and Zwicky, P., 'New evaluation procedure of the waterproofing system for the Swiss Alpine base tunnels', in: (Re)Claiming the Underground Space, Proceedings of the ITA World Tunneling Congress 2003 (Ed. J. Saveur, Publisher Swets \& Zeitlinger B.V., Lisse, NL) 1 (2003) 441-447. 